\title{
"MEDIOS DE COMUNICACIÓN Y VIOLENCIA CONTRA LAS MUJERES. ELEMENTOS DE VIOLENCIA SIMBÓLICA EN EL MEDIO TELEVISIVO"
}

https://doi.org/10.17979/relaso.2011.1.1.1199

\author{
Profa. Dra. Rita $M^{a}$ Radl Philipp \\ Centro Interdisciplinario de Investigacións \\ Feministas e de Estudos do Xénero -CIFEX-USC
}

\section{Summary}

This article about mass media and violence against women, tries in a special way the relationship between the television media and the symbolic elements of violence which are operating to female gender identity from a human socialization point of view. Starting with a conceptual clarification of the terms "gender violence" and "violence against women" we focus the question of the ideological regressive function of the media to female and male gender roles. Because media operates systematically with a superrepresentation of male protagonism and a underrepresentation of female protagonism, the mass-media produce in fact a symbolic violence against women. At last we present a few first empirical research results about the news in the Television in Spain.

Key words: Violence against women, human socialization, Gender roles; mass media; ideological regressive function, symbolic violence.

\section{Resumen}

Este articulo sobre medios de comunicación y violencia sobre las mujeres, trata de modo específico de la relación entre el medio televisivo y los elementos de la violencia symbólica que actúan para con las identidades de género femenino. Partiendo de una aclaración conceptual de los términos violencia de género y violencia contra las mujeres, enfocamos la cuestion de la función ideológicamente regresiva de los medios en relación con las identidades de género femenino y masculino. Como operan de manera sistemática con una sobrerepresentación del protagonismo 
masculino y una subrepresentación del protagonismo femenino, los medios de comunicación de masas modernos producen en realidad una violencia simbólica contra las mujeres. Finalmente presentamos de forma escueta unos primeros datos empíricos procedentes de una investigación sobre las noticias de la televisión en España.

Palabras clave: Violencia contra las mujeres, socialización humana, roles de género. medios de comunicación, función ideológico-regresiva, violencia simbólica

\section{Introducción}

Cualquier óptica científico-social que se acerca a una explicación de la sociedad moderna no puede eludir el considerar la influencia de los medios de comunicación, si bien se va evidenciando que éstos se transforman y van incorporando estilos, usos, expresiones y formas nuevas. Así, los nuevos medios de la información, internet, el uso de la telefonía móvil, los videojuegos, los hábitos en relación con éstos -sobre todo en la generación de las personas jóvenes-, apuntan de antemano a un interés para el contexto sociológico que procede de su valor específico desde perspectivas sociológicas múltiples. En este sentido, aún cuando las modernas tecnologías de la comunicación e información desplazan, al menos en parte, a los medios de comunicación más clásicos, como los escritos y los audiovisuales (prensa escrita, radio, televisión), éstos siguen ocupando, sin duda, un lugar central en la vida de las personas en las sociedades actuales; intervienen de modo decisivo en la construcción de su realidad.

Dos aspectos claves en lo tocante al poder mediático y su intervención en la "construcción social de la realidad"1 son, por una parte, el referido al significado de los medios de

\footnotetext{
$1 \mathrm{El}$ proceso de la comunicación humana representa, efectivamente, en el sentido amplio del término, el mecanismo más relevante para la construcción social de la realidad desde el punto de vista del sujeto socialmente competente, y concretamente apuntando al significado socializador de los medios entroncamos con la idea central de la obra, ya clásica, de Peter Berger y Thomas Luckmann: Berger, P. y Luckmann, T. (1989): La construcción social de la realidad, Buenos Aires, Amorrortu.
} 
comunicación para la socialización humana y, por otra, el propio significado mediático para con las identidades de género.

En el presente texto es nuestro propósito especial adentrarnos en la problemática: medios de comunicación $y$ violencia contra las mujeres, temática que aborda el significado de los medios de comunicación en relación con su influencia en la violencia contra las mujeres. Tal propósito enuncia que las identidades femenina y masculina, esto es, las identidades de género, constituyen un objeto relevante de la influencia mediática, puesto que explícita o implícitamente, están presentes en todas las imágenes y en todos los mensajes mediáticos y, por ende, adquieren el carácter de instancias socializadoras centrales desde una óptica de las identidades de género, cuestión particularmente relevante, si cabe, en un escenario social en el cual la violencia contra las mujeres en vez de disminuir persiste o incluso parece aumentar. Nuestro enunciado básico hace además especial hincapié en el hecho de que la violencia contra las mujeres está estrechamente vinculada al devenir de la socialización humana y sus dinámicas particulares.

En el contexto que nos ocupa defendemos la tesis de que los medios de comunicación modernos no solo son productores de la información en los casos de la violencia contra las mujeres, si no que realmente producen elementos de violencia, eso sí, de tipo simbólico con respecto al rol de género femenino, o sea, inciden en la producción de una "violencia simbólica" contra las mujeres, perceptible ya en la presencia/ausencia de éstas y de sus imágenes en los medios de comunicación de masas modernos. Estos últimos contribuyen a una representación constantemente falseada de la realidad social mediante una sobrerrepresentación del protagonismo masculino y de una subrepresentación del protagonismo social femenino.

De modo concreto efectuaremos, en primer lugar, un abordaje conceptual, aclarando las voces Violencia de Género y Violencia contra las Mujeres. En segundo lugar, hablaremos de la interrelación violencia contra las mujeres y medios de comunicación y a continuación de la función ideológicamente regresiva de los medios para perfilar, en el cuarto punto nuestra 
argumentación en torno a la interrelación medio televisivo y violencia simbólica. Terminaremos con la presentación de algunos datos empíricos procedentes de un proyecto de investigación, relativo a las noticias de la Televisión en España2.

\section{1.- Violencia de Género y Violencia contra las mujeres}

Tal y como recogen diversas entradas enciclopédicas al respecto, el vocablo violencia denota un acto caracterizado por la intimidación, el dominio y la fuerza, se enmarca a menudo en una constelación de poder y apunta, efectivamente, a actos que recurren a "la fuerza y la intimidación para conseguir algo"3.

Abundando en la noción etimológica, el término que constituye el núcleo central de nuestras aseveraciones en este instante, procede del latín "violentia", cuya significación señala fuerza y carácter violento o cruel. Además, se utiliza particularmente el término "opes violentiae" en el sentido de poder tiránico, expresión esta última que tiene una connotación expresamente fuerte de coacción y de dominio en relación con el sujeto (o sujetos) contra el que se actúa con violencia.

La noción conceptual no se delimita a actos estrictamente fisicos, asimismo se refiere a la violencia verbal, psiquica y sexual, concretamente en el ámbito del derecho, en el que también se reconoce la coacción como una forma de violencia.

Ahora bien, parece ciertamente importante resaltar, y sobre todo haciendo especial hincapié en el contexto preciso que nos concierne aquí, que la violencia no existe solamente como un hecho físico, verbal, psíquico y sexual, sino también como un hecho estructural que actúa a lo sumo de forma simbólica. Es más, la violencia puede constituir de igual modo una propiedad de la estructura social, ante todo cuando aparece de forma reiterada, sistemática y en multitud de ámbitos socialmente

2 Agradecemos especialmente la subvención recibida de la Xunta de Galicia, para la realización de este proyecto de investigación titulado: "Socialización en función del género, Medios de Comunicación y Violencia contra las Mujeres, Un análisis sociológico". (PGIDT 05PXI 321401 PR, Xunta de Galicia 2005-2008).

3 Diccionario Enciclopédico Espasa, 1994, tomo X, pág. 2.552. 
relevantes como un atributo "aceptado"; tal es el caso de las conductas agresivas que justifican la ambición y la competitividad que encontramos en el campo laboral, económico y político en las sociedades industriales modernas.

En este sentido la existencia de múltiples situaciones en las que a las mujeres les es impedido que actúen libremente o que puedan desarrollar sus actividades sin coacción, representan situaciones de violencia para éstas.

Los mecanismos y esferas específicas varían; van desde agresiones físicas, ataques psicológicos $y$ verbales $\mathrm{y}$ representaciones e imágenes vejatorias hasta el maltrato económico y sexual. Existen formas y situaciones muy variadas de maltrato en las relaciones sociales, y concretamente en las relaciones intergénero, pero llama la atención que de modo preeminente aparecen como víctimas una y otra vez mujeres. Sin embargo, de un tiempo a esta parte, "la expresión violencia contra las mujeres' empezó a desaparecer del lenguaje oficial y de los medios de comunicación"4. Haciéndonos eco de la afirmación de $\mathrm{M}^{\mathrm{a}}$ Milagros Rivera Garretas, se vio substituida particularmente por el concepto violencia de género, término que finalmente aparece, según es sabido en la legislación española, esto es, en la Ley de "Medidas de Protección Integral contra la Violencia de Género"5.

En el presente marco partimos del presupuesto de que la violencia contra las mujeres no es en realidad una violencia de género que parece afectar a mujeres y varones. Estamos refiriéndonos a un tipo de violencia cuyas víctimas son las mujeres por el simple hecho de ser mujeres, de pertenecer al sexo femenino y, en efecto, por su condición social de género. E1 término "violencia de género" en cambio, y a nuestro juicio, anticipa una constelación hipotética de simetría intergénero inexistente en la cual la violencia se puede dar entre hombres y mujeres en una dirección u otra, aún cuando se suele reconocer con frecuencia, y de hecho la mencionada ley de "Medidas de

\footnotetext{
4 Rivera Garretas, María Milagros (2001): "La violencia contra las mujeres no es violencia de género", Duoda, Revista de Estudios Feministas, 21: 37-42.

5 Ley Orgánica $1 / 2004$, de 28 de diciembre.
} 
Protección Integral contra la Violencia de Género" así lo reconoce en su preámbulo, que en nuestras estructuras sociales se acomete esta violencia prioritariamente contra las mujeres 6 . E1 manejo terminológico "violencia de género" "olvida que son hombres que ejercen la violencia en cuestión, y somos las mujeres quienes la padecemos"7.

Nuestra postura coincide solo en parte con la de otras autoras feministas que introducen la interesante distinción entre género y "corporeidad" para poner de relieve como la violencia contra las mujeres actúa contra "la libertad femenina" como "...libertad relacional, libertad que una mujer prueba y disfruta en relación de confianza con otra; otra que da vínculo, intercambio $y$ medida. Es la libertad que a una mujer corresponde a causa de su ser mujer y no a pesar de su sexo"8. Esto es, se comprende que la violencia contra las mujeres actúa atacando la forma que les es propia a las mujeres para relacionarse de un modo intrinsicamente femenino maternal con su mundo y, a la postre, arremete contra la esencia de su ser. La violencia de género se ve desde esta perspectiva como una "lucha de poder entre los sexos que ejercen muchas veces los hombres $y$, algunas veces, las mujeres"9.

Para nuestro contexto insistimos en una interpretación desde una óptica epistemológica-critica del uso conceptual género. Es decir, observamos como la utilización actual de este término en el campo de los estudios de las mujeres y del género, refleja que esta misma concepción se convierte cada vez más en un constructo que diluye las implicaciones crítico-ideológicas que desde los inicios han definido explícitamente las investigaciones feministas. La voz género adquiere la noción de un concepto axiológicamente neutral. Esta tendencia se extiende de lleno al significado lingüistico del constructo conceptual violencia de

\footnotetext{
6 Sin embargo, las estadísticas en España reflejan asimismo a varones como víctimas.

7 Rivera Garretas, María Milagros (2001). o.c. p. 37

8 Rivera Garretas, María Milagros (2001) o.c. p. 40. La autora retoma especialmente la concepción de libertad de Lía Ligarini y de Luisa Muraro.

9 Muraro, Luisa (1994): El orden simbólico de la madre, Madrid, Horas y horas. Pp. 101-105. Traducción de B. Albertini, M. Bofia y M ${ }^{a}$. M. Rivera, y, Rivera Garretas, M ${ }^{a}$ M (2001), o.c. Pp. 38 y 39.
} 
género. Cabe recordar que los women's studies se concebian, ante todo, como proyectos críticos y crítico-sociales comprometidos con la transformación de la situación vital de las mujeres, y por consiguiente, también de los varones. En estos momentos el término género está perdiendo su valor crítico-ideológicoexplicativo, transformándose de hecho a menudo en un concepto científico descriptivo, realmente vacío de contenido estructural específico, de dudosas pretensiones de "objetividad" en la línea de los paradigmas cientifico-modernos al uso.

En este sentido cabe destacar, que existe un empleo poco preciso y en parte confuso del concepto citado que tiene unas repercusiones especialmente negativas para la consideración adecuada del problema del que nos ocupamos de modo específico en este articulo, es decir, de la violencia y las agresiones sufridas por parte de las mujeres en las sociedades contemporáneas. Para mayor abundamiento y con el propósito de seguir en nuestra línea de argumentación, encontramos asimismo las voces "violencia doméstica", o "violencia familiar", conceptos que se aceptan como términos técnicos sobre todo en el área judicial, política, psicológica y científica10.E1 uso terminológico mencionado denota, como minimo, una falta de rigor, si bien en términos sociológicos encubre ideológicamente una falsificación del hecho violento cuyas víctimas son de manera reiterada las mujeres. Los vocablos citados enfocan a la problemática como un hecho que se sitúa fuera de las constelaciones verticales de poder que siguen caracterizando las relaciones intergénero en la actualidad. En otras palabras, acusamos, en efecto, un empleo terminológico que despoja a la violencia contra las mujeres de su significado estructural real que apunta, por otra parte, a la misma raíz social de la cual emerge el problema, importante, desde luego, de cara a su solución, si cabe definitiva. Pues bien, el empleo del constructo conceptual género como categoría neutral que incluya a mujeres y hombres y que indique una reciprocidad en las relaciones, o bien, una hipotética situación de reciprocidad y de anticipada igualdad en éstas, que en las estructuras sociales modernas, aunque exista garantizada por el

10 Muchos de los trabajos científicos clásicos que tratan el tema emplean estos conceptos, por ejemplo: M.A. Strauss y R.T. Gelles, 1980 y 1988; G. Hotaling, 1990 y P. Langan, 1986. 
derecho no existe de hecho, es, desde luego, epistemológicamente inadecuado. Estamos ante una aplicación conceptual incorrecta, ya que la violencia de género que afecta a mujeres y varones de la misma manera no existe. La violencia que se ejerce contra las mujeres es una violencia sexista, una "agresión a la mujer" (Lorente Acosta, M. 2001: 37 y ss). Se debe a su condición social de género específica en tanto que mujer, y por tanto es, de facto, una violencia "sexista". Con todo, preferimos, por ser más claro, el constructo terminológico "violencia contra las mujeres" o "violence against women", que es además el que se emplea más preferentemente en el contexto internacional.

\section{2.- Violencia contra las Mujeres y Medios de Comunicación}

Para ahondar en una mayor dilucidación de nuestra posición teórica, haremos especial hincapié en la definición ofrecida en su dia por Johan Galtung. Este autor distingue entre violencia directa, violencia estructural y violencia cultural ${ }^{11}$. La primera, esto es, la violencia directa permite la identificación inmediata de un autor y su vinculación con un acto de violencia, mientras que la violencia estructural emerge y forma parte de la estructura social, estando presente en las formas sociales y estructurales de la explotación y marginación de las personas. Por el contrario, la violencia cultural y sus formas perduran básicamente bajo las mismas apariencias culturales especificas durante espacios de tiempo largos. Este tipo de violencia incluye las legitimaciones, represiones culturales y sus representaciones simbólicas respectivas, si bien las acciones corresponden obviamente a la violencia directa. La violencia estructural en cambio, actúa de modo sutil bajo las formas diversas del ejercicio de poder y de la dominación social, política, económica, etc. Tal y como aduce el autor, las interacciones y combinaciones entre estos tres tipos de violencia son múltiples. Entre si componen

11 Siguiendo este modelo podemos analizar las raices estructurales y culturales de la violencia directa, y en el caso de la violencia contra las mujeres nos permite desarrollar un enfoque, esto es, una óptica "multidimensional" para el análisis científico. Vid. Galtung, J. (1990): "Cultural Violence", Journal of Pace Research, 27, 3: 291-305. 
ciertamente un triángulo interconectado del cual desde cualquier elemento se puede transmitir fácilmente la violencia a otro 12 .

Aplicando este modelo de análisis al tema concreto que constituye el núcleo central de las reflexiones en el presente marco, podemos perfilar nuestra argumentación acerca de la tesis de que la violencia ejercida contra las mujeres es realmente una violencia estructural-sexista, es decir, constituye un fenómeno socioestructural que actúa usando infinidad de elementos culturales diversos en los múltiples ámbitos: social, científico, económico, político y laboral. Se trata de un tipo de violencia fundamentado en unas definiciones de género verticales que implementan, a su vez, unas interrelaciones caracterizadas por el ejercicio de poder y de dominio de un género frente a otro en una estructura social concreta. El modelo cultural y estructural de fondo corresponde al androcentrismo en todas sus facetas. La dimensión cultural y estructural de la violencia ya no solo tiene a su servicio unos mecanismos simbólicos aislados, sino todo un entramado de elementos simbólicos vinculados a instancias que de modo aparente se encuentran alejados de contenidos ideológicos precisos, pero que ejercen una fuerza ideológica tal que garantizan la reproducción eficaz de la estructura androcéntrica de fondo. A los medios de comunicación de masas modernos y a los nuevos medios tecnológicos de la comunicación e información (televisión, internet, videojuegos, telefonía móvil, etc.) les corresponde aquí un lugar preferente entre estas instancias, puesto que operan simbólicamente con modelos que reproducen y ejercen sutilmente una violencia simbólica contra las mujeres a través de formas múltiples sirviéndose de elementos culturales y sociales aceptados y aparentemente "correctos" y "neutrales", por ejemplo, a través de la representación tradicional de los roles de género, de la subrepresentación de las mujeres, de un falso superprotagonismo masculino y la transmisión de comportamientos estereotipados que no corresponden a la realidad plural existente. El androcentrismo aporta la legitimación cultural y estructural de la violencia directa y la justificación ideológica de las normas de acción para perpetuar la

12 Ibidem.

Revista Latina de Sociología, $\mathrm{n}^{\circ}$ 1: 156-181

http://revistalatinadesociologia.com ISSN 2253-6469 
discriminación de las mujeres y mantener la verticalidad de las relaciones intergénero.

\section{3.- Género y función ideológicamente regresiva de los Medios}

Desde una perspectiva de socialización y educación humana que pone de relieve el poder constructor de la comunicación mediática y, efectivamente, el poder socializador resultante de los medios a través de la transmisión de significados, los medios de comunicación inducen de facto a la construcción de la realidad social circundante facilitando al mismo tiempo las herramientas para la interpretación del significado mediático.

Con la mirada puesta en la investigación mediática feminista, ésta aporta por una parte, enfoques teóricos que destacan que los estereotipos se deben a la simple existencia de los mismos en la sociedad, esto es, que defienden una concepción reproduccionista en cuanto a la dinámica mediática y su significado para la sociedad (Gallego, J., 1990, Dominguez Juan, $\mathrm{M}^{\mathrm{a}}$ M., 1988). Por otra parte encontramos posiciones que sostienen que la situación de las mujeres en los medios está estrechamente vinculada a la subrepresentación de las mismas en las redacciones y en los puestos directivos (Van Zoonen, 1988)13. Asimismo hallamos posturas teóricas que hablan ya abiertamente de una "función regresiva" de los medios (C. Fagoaga, 1993)14 para con el rol femenino aduciendo que los medios de comunicación en absoluto representan de forma neutral a los fenómenos socialmente importantes, ni tampoco siguen operando con unos estereotipos por razones de un "retraso ideológico" a tenor de una dinámica social más avanzada. Por el contrario, sugieren que los medios cumplen efectivamente una función ideológica que favorece el mantenimiento de unas estructuras de poder, que en el caso del rol femenino, es una función ideológicamente regresiva, ya que las mujeres no llegan a

13 Vid. Van Zoonen, L. (1988): "Rethinking Women and the News, European Journal of Communication, 3: 35-53.

14 Vid. Fagoaga, C. (1999): La violencia en los medios de comunicación. Maltrato a la pareja y agresión sexual, Madrid, Comunidad de Madrid. Sobre todo págs. 100-101. 
ser retratadas en la comunicación mediática con las funciones sociales que realmente desempeñan.

De modo más claro; los medios de comunicación de masas inciden en la reproducción y producción de una realidad social mediante la transmisión de elementos falsos y trastocados en relación a los roles de género. Estas aseveraciones se sitúan en una línea epistemológica que rompe con una mera crítica representacionista y defiende una posición teórico-constructivista que presta especial atención a la función "constructora" de los medios con vistas a los roles de género enlazando con la convicción semiótica de que el lenguaje, las imágenes y la comunicación en general construyen y generan la propia realidad a la vez que ofrecen el bagaje simbólico para reconstruirla.

En nuestros trabajos y asimismo para el contexto que centra nuestra atención específica en este instante, defendemos una concepción constructivista-interaccionista que pone de relieve el poder constructor de los medios de comunicación y, en definitiva, la capacidad socializadora de los medios que surge de la transmisión de significados. Facilitando las herramientas para la interpretación del propio significado mediático, la comunicación mediática induce, de facto, a la construcción de la realidad social circundante. Esta postura va más allá de un análisis de las diferencias entre mujeres y varones o de una crítica de los estereotipos existentes; parte de la tesis de que los medios de comunicación, el lenguaje y la comunicación en general construyen al mismo tiempo que reproducen la realidad.

Abundando en esta visión, se evidencia que unas imágenes ajustadas a la realidad tendrán un efecto socializador distinto que unas imágenes equivocas. En concreto y en lo tocante a nuestro tema no es lo mismo que se dé una representación falseada mediante la sobrerrepresentación masculina y la subrepresentación femenina, por cuyo motivo hemos llegado a acuñar la clasificación conceptual: "función ideológica regresiva"15 de los medios de comunicación en relación con los

15 Este término lo hemos introducido en nuestros primeros trabajos sobre la imagen de las mujeres en los programas de debates en la televisión. Véase: Radl Philipp, R. (1995): "La nueva identidad de género femenino en los debates de la televisión”, en R. Radl Philipp y 
roles de género. Esto es, desde una óptica de la socialización humana, la comunicación mediática implementa y mantiene una visión anclada en un dominio masculino omnipresente en todas las representaciones e informaciones, a pesar de que la propia realidad social muestra unos parámetros distintos acerca del protagonismo social de mujeres y varones, ejerciendo con ello una función ideológico-regresiva en lo concerniente al rol de género femenino y masculino que reproduce de forma sistemática los estereotipos androcéntricos en la "conciencia colectiva" de los sujetos, usando una concepción ya clásica y original referente a la función socializadora de la educación, desde luego ampliamente conocida, del renombrado Emile Durkheim 16.

Partimos de un enfoque teórico de reconstrucciones activas en lo relativo a los medios de comunicación, una postura interaccionista aún cuando las comunicaciones que se establecen entre el medio y el sujeto receptor poco tienen que ver con comunicaciones reciprocas, o bien, con interacciones simétricas que suponen el punto de partida de los análisis teóricointeraccionistas. En el presente marco nos apoyamos en el presupuesto de que el lenguaje así como los símbolos mediáticos expresan, esto es, representan la realidad al mismo tiempo que intervienen en su construcción en la línea de lo descrito por G.H. Mead para el tema de la comunicación a través de los simbolos significantes 17 . En este sentido nos centramos en el aspecto "semiótico" que Van Zoonen diferencia del análisis de contenido, dado que nos interesa ante todo el aspecto constructivo del lenguaje y de la comunicación, aspecto éste que alude al hecho de

$\mathrm{M}^{\mathrm{a}}$.C. García Negro, (ed.), As Mulleres e os cambios sociais e económicos, Santiago de Compostela: Universidade de Santiago de Compostela; y Radl Philipp, R (1996): "Los medios de comunicación de masas y sus imágenes femeninas", en $\mathrm{M}^{\mathrm{a}} \mathrm{A}$. García de León y $\mathrm{M}^{\mathrm{a}} \mathrm{L}$. García de Cortazar (ed.), Sociología de las mujeres españolas, Madrid, Editorial Complutense. Pp. 367-384.

16 Vid. Durkheim, E. (1991): Educación y Sociología, México, Ed. Colofón.

17 Mead diferencia entre el gesto simple y el gesto, o bien simbolo significante. El último es aquél que expresa la idea que representa y que al mismo tiempo, logra generar esta misma idea en otros seres humanos. El símbolo significante más importante que reúne todas estas características es el símbolo lingüístico. Véase, sobre todo Mead, G. H. (1972): Espíritu, persona y sociedad, Barcelona, Paidós. Recuerdo aquí también las aportaciones de Watzlawick y Habermas sobre los dos aspectos fundamentales de la comunicación, el del contenido y el de la relación. Watzlawick et al (1983): Teoría de la Comunicación Humana, Barcelona, Herder. $3^{a}$ Ed. 
que los símbolos son símbolos de la realidad y no símbolos que solo sirven para representarla 18 .

Una visión de este tipo nos permite, a pesar de todo, comprender los procesos de la socialización humana como procesos en los cuales el sujeto, en tanto que ente activo y constructivo que es, también puede contrarrestar, a pesar de su dificultad, el efecto negativo que proviene de la función ideológicoregresiva de los medios, siempre y cuando existan unas condiciones socio-educativas adecuadas para que los sujetos puedan proceder a unas interpretaciones y esbozos de roles propios.

\section{4.- Medio televisivo y Violencia Simbólica}

Siguiendo con nuestras aseveraciones y enlazando con las conceptualizaciones anteriormente introducidas, recordando particularmente la definición de Johan Galtung, la fuerza ideológicamente regresiva de los medios genera una violencia simbólica para con el rol social de las mujeres, dado que en los medios se efectúa una representación sesgada de las féminas, no son representadas a través de sus múltiples funciones que desempeñan de facto en la sociedad. En cambio, la dinámica mediática mantiene en la conciencia de las personas una percepción ideológica de la realidad con tintes claramente androcéntricos que impregnan las conductas particulares, a través del dominio masculino falso que muestran.

El término "violencia simbólica" es introducido en la discusión sociológica en el año 1970 por Pierre Bourdieu y Claude Passeron en su libro "La Reproduction", a lo sumo, para referirse al sistema educativo, esto es, de la enseñanza, en las sociedades modernas 19. Cualquier acto educativo-pedagógico procede, según su definición, básicamente siempre contra la voluntad del educando debido a que exige de él un sometimiento

18 Van Zoonen, L. (1994). Feminist Media Studies, London, Sage. Pp. 65 y ss.

19 Así lo relata detalladamente el propio título completo de la obra: Bourdieu, P. y Passeron, J.C. (1970): La Reproduction. Élément pour une théorie du systeme d'enseignement, Paris, Ed. Minuit. En castellano (1977): La reproducción. Elementos para una teoría del sistema de enseñanza, Barcelona, Laia. Traducción y prólogo de Marina Subirats. 
al poder del agente educador. Este último, por otra parte, educa a los sujetos de forma arbitraria de acuerdo con los valores y normas sociales del grupo de poder dominante excluyendo al mismo tiempo los valores de los demás grupos sociales. Añadiendo su propio valor pedagógico al quehacer educativo éste actúa de forma que garantiza doblemente la reproducción de la estructura e ideología capitalista dominantes agrandando las diferencias iniciales existentes al comienzo del proceso educativo en cuanto al capital cultural de los sujetos. Tal acto pedagógico arbitrario es siempre violencia simbólica, ya que no actúa de forma directa o física, se mueve siempre en la esfera ideológica de modo encubierto.

En el contexto que nos ocupa es relevante subrayar, aún cuando se puede entender que conectamos en un sentido muy amplio con esta definición sociológico-educativa y teniendo presente que Bourdieu utiliza en 1998 el vocablo violencia simbólica en relación con la representación femenina en los medios -que califica como elementos de la reproducción simbólica $20_{-}$, que el significado otorgado en nuestros trabajos va más allá de un prisma de este tipo. Partimos de una concepción que manejamos específicamente en nuestros trabajos ya desde el año 1995 a tenor de la función ideológico-regresiva de los medios en relación con el rol de género femenino en un sentido estrictamente epistemológico-crítico-feminista, si cabe, conceptualización que parte a la postre de una perspectiva centrada en la constelación vertical del poder inherente a las relaciones intergénero. Según nuestra definición de violencia simbólica, ésta se ejerce siempre contra las mujeres estando vinculada a una constelación de poder intergénero androcéntrica, sea de modo explícito o implícito, remite a normas socialmente aceptadas y persigue la reproducción de tales relaciones androcéntricas de poder.

\footnotetext{
20 Véase Bourdieu, P. (1998): La Domination masculine, Paris, Ed. du Séuil; donde, por cierto, participa asimísmo de esta dominación masculina, eludiendo cualquier referencia a alguna autora femenina sobre la temática. Será por las estructuras androcéntricas inconscientes por cuyo motivo no reconoce las aportaciones de las autoras cientificas y feministas a sus elucubraciones teóricas. En castellano (2000): La dominación masculina, Barcelona, Anagrama.
} 
Con todo, no cabe duda de que la función ideológicamente regresiva de los medios en relación con los roles de género en su dimensión simbólica y, en especial, de violencia simbólica que actúa para con las mujeres, tiene un valor especialmente negativo desde una óptica de socialización y educación humana debido a la dinámica propia de estos procesos, que cuando tienen lugar en edades muy tempranas son altamente difusos y en gran parte inconscientes y semiconscientes. Para un mayor abundamiento; inciden en un devenir que caracteriza a los procesos primarios de identificación humana en cuyo transcurso el ser humano se percibe desde el primer momento en el cual toma conciencia de su "si mismo" (nosotros/nosotras) como un ser, un sujeto sexuado. Su identificación en tanto que persona no es como tal, sino como persona de sexo masculino o femenino, como "niña" o "niño", hecho que le comporta, en efecto, su "Identidad de Género". De allí se deriva el significado de lo que denominamos, si cabe, la doble dimensión de violencia simbólica que ejercen los medios de comunicación de masas modernos, en especial el medio televisivo, atinente al rol de género femenino a través de su fuerza socializadora. Esta doble dimensión de violencia simbólica proviene del hecho de que a parte de las repercusiones negativas que supone desde un ángulo propiamente socializador, impide fuertemente unos procesos de cambio necesarios precisamente en lo que a la violencia contra las mujeres se refiere.

\section{5.- Algunos datos empiricos}

En nuestras investigaciones empiricas defendemos la tesis de que los medios de comunicación de masas modernos cumplen de modo global una función ideológicamente regresiva para con el rol del género femenino de manera que inciden y favorecen el mantenimiento de unas estructuras de poder que tienen todos los rasgos de ser androcéntricas. Esto es, el androcentrismo entendido como modelo social y cultural que atañe tanto a las convicciones y pensamientos personales, como al comportamiento institucional y a los esquemas que dominan en los diversos campos específicos de la sociedad, como es el caso de los ámbitos laboral, familiar, social, cultural, político, económico 
y científico, por ejemplo. En la lógica androcéntrica el varón constituye el modelo cultural por excelencia, el centro del mundo y de la vida social, económica, política etc., constituye el modelo que envuelve todo $\mathrm{y}$, por tanto, el modelo simbólico-cultural dominante, inherente a todos los aspectos de la organización social y cultural. A partir de este modelo se otorgan valoraciones y clasificaciones de toda indole, implícita y explícitamente, a lo que acontece en el seno de la misma sociedad en el ámbito de la vida institucional y personal en relación con los sujetos.

Nuestra hipótesis central atañe a las imágenes y mensajes mediáticos que pertenecen a su vez a medios y campos mediáticos diversos, si bien los datos empíricos proceden del medio televisivo, sin duda, junto con las nuevas tecnologias de la información, el más poderoso en las sociedades actuales. Las investigaciones en relación con la presente temática, muestran, sin embargo, como los datos sobre la prensa escrita, las noticias, los diarios, la prensa femenina e incluso la literatura infantil, se pueden interpretar en este mismo sentido.

Los resultados de una investigación específica nuestra sobre los telediarios de mayor audiencia en España (en su momento el telediario del mediodía en Antena 3 TV y el telediario de noche en Televisión Española TV 1) revelan que las imágenes, en cuanto a las funciones transmitidas referentes a mujeres y varones, corresponden realmente a representaciones falsas; ofrecen una imagen trastocada de la realidad a la vez que aportan los elementos que intervienen en una "falsa reconstrucción" de la misma. Aquí solo presentaremos algunos datos parciales de la primera parte de la investigación, pero relevantes para el presente contexto. La segunda parte de la investigación, a la que excede el presente marco, se centra en los efectos socializadores del medio televisivo en una muestra representativa de jóvenes entre 13 y 15 años, habiendo obtenido los datos a través de cuestionarios y grupos de discusión.

Para nuestro análisis registramos 2.767 noticias, cuyos datos habian sido recogidos entre los meses de mayo y octubre del año 2007. Si bien los resultados ofrecen una primera aproximación empírica, corroboran que el tratamiento mediático, 
sus representaciones e imágenes, reflejan una realidad social falsa desde una perspectiva de género.

Así podemos apreciar en el gráfico 1, como en el $91,2 \%$ de las imágenes de las noticias aparecen varones. Solo en un $8,8 \%$ de las mismas están ausentes, mientras que en el 24,1\% de las noticias no se detecta ninguna presencia de mujeres, que, eso sí, salen en el 75,9\% de las imágenes de las noticias.

\section{Gráfico 1: Presencia en las imágenes de las noticias en función del género (\%)}

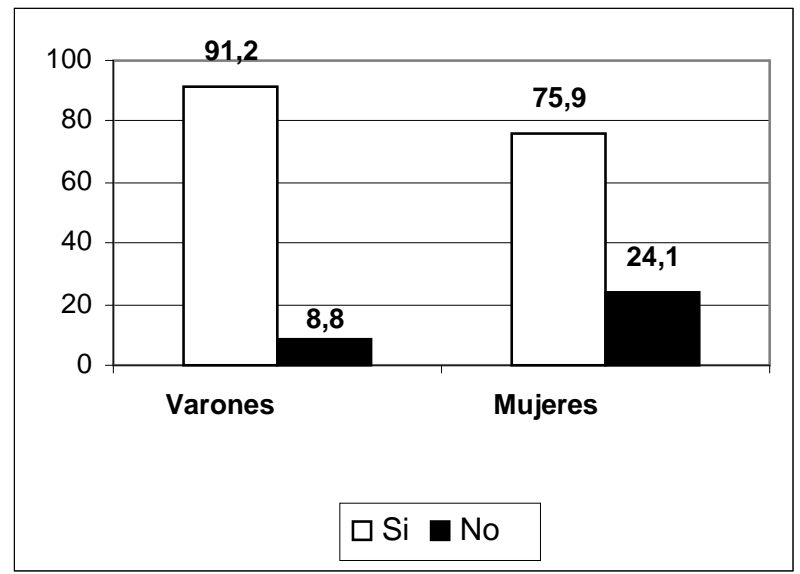

Fuente: Elaboración Propia

La dominante presencia masculina se refuerza en todas las variables investigadas. En cuanto a la aparición de varones que son entrevistados en las noticias y, por tanto, se pronuncian, se sitúa la cifra en un $51,9 \%$ frente al $27,1 \%$ de mujeres. Se trata de un panorama ciertamente desequilibrado desde una óptica diferencial del género, tal y como podemos ver en el gráfico 2 . 


\section{Gráfico 2: Personas con presencia que hablan en las noticias, análisis diferencial de género (\%)}

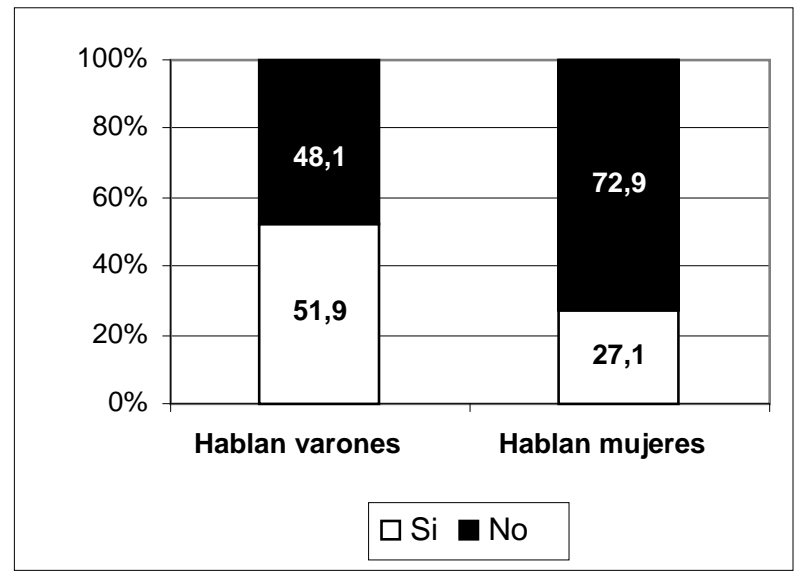

Fuente: Elaboración Propia

Sobresale, además, en el mencionado gráfico 2 que en un $72,9 \%$ de las imágenes transmitidas en las que aparecen las mujeres éstas no hablan, solo toman la palabra en el $27,1 \%$ de las mismas, lo cual quiere decir que ni siquiera en la tercera parte de las noticias retratadas llegan a poder manifestarse. Por el contrario, los varones hablan en el $51,9 \%$ de los casos frente al $48,1 \%$.

El análisis global en función del género, esto es, de la distribución porcentual total de las personas que hablan en las noticias, muestra un dominio aún mayor de los varones (gráfico 3). Los varones hablan en el $69 \%$ de todas las noticias en comparación con el $31 \%$ de las mujeres. Es decir, en más de las dos terceras partes se expresa oralmente el colectivo masculino en comparación con el grupo femenino, que, representando más del $50 \%$ de la población, no llega a tomar la palabra ni siquiera en una tercera parte de las noticias. 


\section{Gráfico 3: Distribución porcentual total de las personas que hablan en las noticias según género}

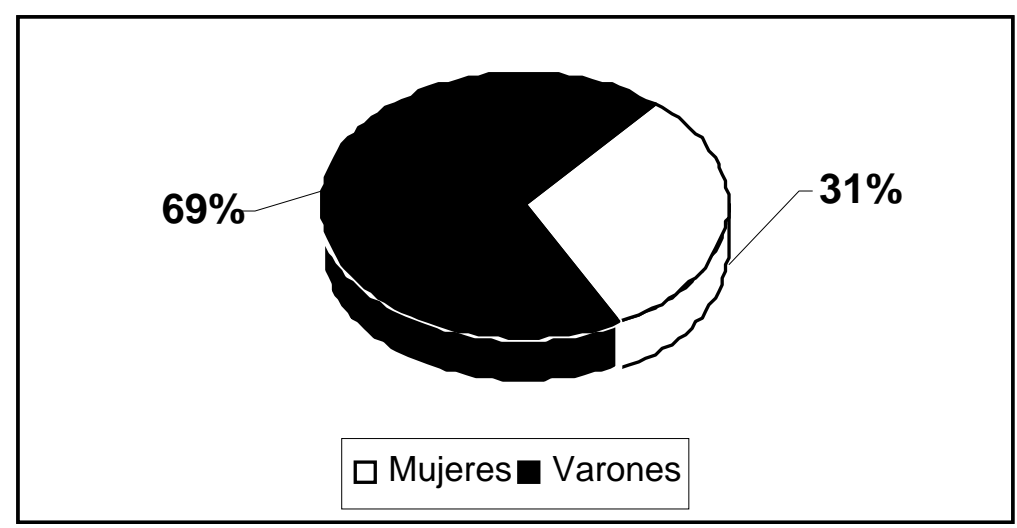

Fuente: Elaboración Propia

La subrepresentación de las mujeres se hace aún más palpable efectuando un análisis desde el ángulo de las frecuencias temporales. Los varones toman la palabra siempre en las intervenciones más largas, en las que duran más de 6 minutos hablan el 100\%. Las mujeres, en cambio, solo intervienen aquí en un $50 \%$ de las noticias.

En las noticias cortas, de 1 minuto, se manifiestan también los varones todavía en el $72,7 \%$ de los casos. Al grupo femenino le corresponden aquí solo el 40,2\% de las alocuciones, hecho que señala que en las intervenciones orales, en la "visibilidad oral", las diferencias negativas para las mujeres se agrandan aún más. Esta tendencia en cuanto a las frecuencias de las expresiones orales la habiamos podido constatar ya con anterioridad en otras investigaciones nuestras sobre las imágenes y la presencia de las mujeres en los programas televisivos de debate con temas politicos y sociales diversos, $21 \mathrm{y}$, por tanto, pertenece a una dinámica recurrente que persiste.

\footnotetext{
21 Para los resultados remito a nuestras publicaciones al respecto, sobre todo: Radl Philipp, R. (2001b): "Los medios de comunicación de masas y las imágenes en función del género: sobre la influencia socializadora de la Televisión", en B. Muñoz (ed.), Medios de comunicación y Cambio Cultural, Madrid, Comunidad de Madrid; Radl Philipp, R. 1995, o.c. y Radl Philipp, R. 1996, o.c.
} 
Los datos confirman nuestra hipótesis acerca de la "subrepresentación femenina" y del "superprotagonismo masculino" en el medio televisivo, extremo que en el análisis efectuado por temas se consolida de forma relativa, dado que las temáticas de fuerte prestigio social (economía, ciencia y derecho, etc.) están dominadas por el protagonismo masculino. Con todo, las féminas están siempre subrepresentadas y el colectivo masculino siempre sobrerepresentado; domina la información televisiva de las noticias. En este sentido plasman nuestros datos, de los cuales solo hemos podido presentar aquí de forma sucinta algunos significativos, como, en efecto, los elementos estructurales y culturales de la violencia contra las mujeres está presente en las informaciones, los aspectos auditivos y los contenidos de las noticias analizadas de manera simbólica. La representación mediática no corresponde, en absoluto, al protagonismo real actual de las mujeres españolas. Aún cuando las féminas suman el $75 \%$ en el grupo de presentación, realización y producción de los telediarios, en el medio televisivo los varones son omnipresentes.

Resumiendo, de nuestros resultados se desprende como, efectivamente, desde un punto de vista estructural los elementos culturales de una violencia simbólica para con las mujeres, están presentes, sobre todo teniendo en cuenta que en la investigación referente al efecto socializador en el grupo de los jóvenes (de 1315 años), la identificación de éstos corrobora asimismo como la imagen masculina está asociada al dominio y al poder dando lugar a una consciencia de género connotada por el protagonismo masculino. Así, afirman mayoritariamente que los varones salen en la televisión debido a su "importancia", mientras que las mujeres lo hacen por su "belleza" y sus atributos corporales, y lo declaran en mayor medida los chicos que las chicas 22 .

22 Estos datos proceden de las entrevistas y cuestionarios de chicas y chicos de la muestra (13-15 años) de la $2^{\mathrm{a}}$ parte del proyecto de investigación. Estas percepciones/identificaciones son además más acusadas en el caso del grupo masculino. 


\section{6.- Conclusiones}

Los medios tecnológicos y de la comunicación no solo constituyen un poder en las sociedades modernas, si no que de facto, se han convertido en las instancias más relevantes para la reproducción ideológico-androcéntrica. El tipo de programas analizado opera con modelos que evocan de modo sutil elementos de violencia simbólica para con el rol de género femenino.

Conforme lo ponen de relieve los datos obtenidos en el seno de nuestro proyecto de investigación: "Socialización en función del género, Medios de Comunicación y Violencia contra las Mujeres. Un análisis sociológico" -si bien aquí solamente hemos podido apuntar de forma escueta algunos de los más relevantes $23_{-}$, la realidad transmitida por los telediarios de la TV en España refleja de forma dominante una realidad masculina, los varones son, desde luego, omnipresentes. Tal realidad transmitida a través del espacio televisivo indagado corresponde a una realidad de trazos androcéntricos que impiden a las mujeres una identificación positiva que pudiese tener connotaciones de protagonismo social. Es precisamente en esta dinámica en la que reside la violencia simbólica en relación con el colectivo femenino, la que quedándose en la esfera simbólica de la representación de la realidad, alejado de contenidos explícitos con respecto al género, tiene una significación, eso sí sutil, de violencia para con el rol de género femenino. En los telediarios se invisibilizan y se ocultan a las féminas de forma sistemática, no llegan a ser protagonistas relevantes de la información, y además no tienen voz; cuando aparecen, muchas veces son mudas. Es decir, salen en mucha menor medida y la mayoría de las veces ni siquiera hablan.

Este extremo apunta a un efecto socializador al que, desde luego, hemos de prestar una atención especial desde un punto de vista sociológico educativo, efecto que hasta el momento no se ha tenido lo suficientemente en cuenta sobre todo con vistas a la prevención y educación en relación con la violencia contra las mujeres.

$23 \mathrm{El}$ conjunto de los datos refuerza la tendencia de los datos presentados, como por ejemplo aquellos referentes a los contenidos temáticos y, desde luego, los procedentes del análisis de la percepción por parte de la investigación del grupo de las y los jóvenes. 
Hemos podido apreciar que las mujeres no son sujetos reales de la información en el medio televisivo, así lo demuestran en conjunto los resultados de las noticias investigadas. No se plasma el protagonismo real del grupo femenino en nuestra sociedad, en la cual constituyen ya en estos instantes una mayoría en el segmento joven de bastantes colectivos profesionales de más alta cualificación, como por ejemplo en el grupo judicial, la abogacía, la medicina, etc. siendo, tal y como lo confirman los datos estadísticos al respecto, desde hace casi tres décadas (desde el curso 1985/1986) mayoría entre el alumnado y, más aún, entre la población egresada de las instituciones de educación superior en España. Los telediarios tienen, sin duda, una función ideológicamente regresiva en lo concerniente al protagonismo social de las mujeres.

Los datos empíricos apuntan, en el sentido aquí desarrollado, a una violencia simbólica que ejerce la función ideológicamente regresiva de los medios para con el rol de género femenino, pero posiblemente nos permiten además entender el porqué en estos momentos la gran lacra de la violencia contra las mujeres sigue estando tan presente en nuestras sociedades. La socialización humana recibe por parte de los medios, concretamente del medio la televisivo, los elementos que inciden en la reproducción eficaz de una realidad efectivamente androcéntrica.

\section{Bibliografía}

Berger, P. y Luckmann, T. (1989): La construcción social de la realidad, Buenos Aires, Amorrortu.

Bourdieu, P. y Passeron, J.C. (1970): La Reproduction. Élément pour une théorie du systeme denseignement, Paris, Ed. Minuit. En castellano (1977): La reproducción. Elementos para una teoría del sistema de enseñanza, Barcelona, Laia. Traducción y prólogo de Marina Subirats. 
Bourdieu, P. (1998): La Domination masculine, Paris, Ed. du Séuil. En castellano: (2000): La dominación masculina, Barcelona, Anagrama.

CCOO (2000): El acoso sexual en el trabajo en España, Madrid, Secretaría Confederal de la Mujer.

Diccionario Enciclopédico Espasa (1994), Madrid, Espasa Calpe, Tomo X. P. 2.552.

Domínguez Juan, $\mathrm{M}^{\mathrm{a}}$ M. (1988): Representación de la Mujer en las revistas femeninas, Madrid, Universidad Complutense. (Tesis Doctoral)

Durkheim, E. (1991): Educación y Sociología, México, Ed. Colofón. Fagoaga, C. (1999): La violencia en los medios de comunicación. Maltrato a la pareja y agresión sexual, Madrid, Comunidad de Madrid.

Falcón, L. (1991): Violencia contra la mujer, Madrid, Vindicación Feminista.

Galtung, J. (1990): “Cultural Violence”, Journal of Pace Research, 27, 3: 291-305.

Gallego, J. (1990): Mujeres de papel. De Hola a Vogue: La prensa femenina en la actualidad, Barcelona, Icaria.

Gelles, R. T. (1987): Family violence, Beverly Hills, Sage.

Green, A. H. (1978): "Self-destructive behaviour in baterred children", American Journal of Psychiatry, 135: 579-582.

Goode, E. (1994): Deviant behaviour, London, Prentice Hall International. (4th ed.)

Haraway, D. (1991): Simians, Cyborgs and Women: The reinvention of nature, London, Free Association.

- (2000): “A Cyborg Manifesto", en: D. Bell, y B. Kennedy (eds.), The Cybercultures Reader, London and New York, Routledge.

Hotaling, G., Straus, M. y Lincoln, A. (1990): "Intrafamily violence and crime and violence outside the family", en M. Straus y R. T. Gelles (eds.), Physical violence in american families: 
Risk factors and adaptations to violence in 8.145 families, New Brunswick, N. J., Transaction.

Kantor, G. y Straus, M. (1.990): The Drunken Bum. Theory of Wife Beating, en M. Straus y R.T. Gelles (eds.), Physical violence in american families: Risk factors and adaptations to violence in 8.145 families, New Brunswick, N. J., Transaction.

Langan, P. y Innes, C. (1986): "Predicting domestic violence against women", Bureau of Justice Statistics Special Report, Agosto: 1-5.

Lorente Acosta, M. (1999): Agresión a la mujer: maltrato, violencia y acoso: entre la realidad social y el mito cultural, Granada, Comares.

- (2001): Mi marido me pega lo normal, Barcelona, Ares y Mares.

Martín Serrano, E. (1999): Las violencias cotidianas cuando las victimas son mujeres, Madrid, Instituto de la Mujer.

Mead, G. H. (1972): Espíritu, persona y sociedad, Barcelona, Paidós.

Miedzian, M. (1996): Chicos son, hombres serán: ¿Cómo romper los lazos entre masculinidad y violencia?, Madrid, Horas y Horas, Cuadernos Inacabados.

Muraro, Luisa (1994): El orden simbólico de la madre, Madrid, Horas y horas. (Traducción de B. Albertini, M. Bofia y $\mathrm{M}^{\mathrm{a}}$. M. Rivera).

Nicholson, L. J. (1992): Postmodernismo, Buenos Aires, Feminaria.

Pérez del Campo Noriega, A. M. (1995): Una cuestión incomprendida: e maltrato a la mujer, Madrid, Horas y Horas, Cuadernos Inacabados.

Radl Philipp, R. y García Negro, M.C. (ed.) (1995): As Mulleres e os cambios sociais e económicos, Santiago de Compostela, Universidade de Santiago de Compostela. 
RADL PHILIPP, R. (1995): "La nueva identidad del género femenino en los debates de la televisión", en R. Radl Philipp y $\mathrm{M}^{\mathrm{a}}$.C García Negro (eds.), As Mulleres e os cambios sociais $e$ económicos, Santiago de Compostela, Universidade de Santiago de Compostela, pp.77-96.

- (1996): "Los medios de comunicación de masas y sus imágenes femeninas", en $\mathrm{M}^{\mathrm{a}}$. A. García de León y $\mathrm{M}^{\mathrm{a}} \mathrm{L}$. García de Cortazar, Sociología de las mujeres españolas, Madrid, Editorial Complutense, pp. 367-384.

- (2001a): (ed.): Cuestiones Actuales de Sociología del Género, Madrid, CIS.

- (2001b): "Los medios de comunicación de masas y las imágenes en función del género: sobre la influencia socializadora de la Televisión”, en B. Muñoz (ed.), Medios de comunicación y Cambio Cultural, Madrid, Comunidad de Madrid.

- (2001c): "Acerca del estatus epistemológico-crítico de las investigaciones de género", en R. Radl Philipp, (ed.), Cuestiones Actuales de Sociología del Género, Madrid, CIS.

Rivera Garretas, $M^{\mathrm{a}}$ M (2001): "La violencia contra las mujeres no es violencia de género", Duoda, Revista de Estudios Feministas, 21:37-42.

Rojas Marcos, L. (1996): Las semillas de la violencia, Barcelona, Círculo de Lectores.

Sherman, L. y Berk, R. (1984): "The specific deterrence effects of arrest for domestic assault", American Sociological Review, 49: 261-272.

Straus, M. A. (1991): "Discipline and deviance: Physical punishment of children and violence and other crime in adulthood", Social Problems, 38, Mayo: 133-154.

Straus, M.A., Gelles, R. T. y Steinmetz, S. K. (1980): Behind closed doors: violence in the american family, New York, Doubleday/Anchor.

Straus, M.A. y Gelles, R.T. (1988): Intimate violence, Chicago, University of Chicago Press. 
Van Zoonen, L. (1988): "Rethinking Women and the News", European Journal of Communication, 3: 35-53.

- (1994): Feminist Media Studies, London, Sage.

Ward, D., Carter, T. y Perrin, R. (1994): Social deviance. Being, behaving and branding, London, Allyn and Bacon.

Watzlawick y otros (1983): Teoría de la Comunicación Humana, Barcelona, Herder. $3^{a}$ Ed.

Websdale, N. y Chesney-Lind, M. (1998): "Doing violence to women: Research synthesis on the victimization of women", en Lee A. Bowker (ed.), Masculinities and violence. London, Sage.

\section{FORMA DE CITAR ESTE TRABAJO EN BIBLIOGRAFÍAS HOW TO CITE THIS ARTICLE IN BIBLIOGRAPHIES}

Rad1, R. (2011): "Medios de comunicación y violencia contra las mujeres. Elementos de violencia simbólica en el medio televisivo", Revista Latina de Sociologia, $\mathrm{n}^{\circ}$ 1: 156-181, http://revistalatinadesociologia.com, ISSN 2253-6469 